\title{
Biodiesel purification using polymeric nanofiltration composite membranes highly resistant to hard conditions
}

\author{
Juan J. Torres ${ }^{1}$, Javier Toledo Arana ${ }^{1}$, Nelio A. Ochoa ${ }^{2}$, José Marchese ${ }^{2}$, Cecilia Pagliero ${ }^{1}$ * \\ ${ }^{1}$ Planta Piloto de Ingeniería Química, Facultad de Ingeniería, Dpto. de Tecnología Química, Universidad Nacional \\ de Río Cuarto, R. Nac. №36 km 601, 5800 Río Cuarto, Argentina \\ ${ }^{2}$ INFAP-CONICET-FONCYT, Universidad Nacional de San Luis, Chacabuco 915, 5700 San Luis, Argentina \\ *Correspondence: Cecilia Pagliero (E-mail: cpagliero@ing.unrc.edu.ar), Planta Piloto de Ingeniería Química, \\ Universidad Nacional de Río Cuarto, Facultad de Ingeniería, Dpto. de Tecnología Química. R. Nac. N³6 km 601 , \\ 5800 Río Cuarto, Argentina.
}

\begin{abstract}
In this work biodiesel (BD) purification was carried out with two lab-made solvent resistant composite nanofiltration (NF) membranes of poly(vinylideneflouride) (PVDF) as a support and poly(dimethylsiloxane) (PDMS) as coating layer. BD was obtained from the esterification of partially refined soy oil with bioethanol (EtOH) and $\mathrm{NaOH}$ as catalyst. The best BD purification performance was achieved with the PVDF-12SI membrane reaching retentions of $70 \%$ of glycerol, $69 \%$ of total glycerides, and $40 \%$ of soap. It was remarkably that PVDF-SI membranes have an excellent stability for BD permeation, achieving a Flux Recovery Ratio of EtOH as higher as to 0.94 after 20 cycles of use.

Keywords: Membrane Purification, Biodiesel, Ethyl esters, Nanofiltration, Glycerides.
\end{abstract}

\section{Introduction}

Biodiesel is an interesting alternative of diesel fuel obtained from renewable resources. The massive production of $B D$ is achieved from the reaction between triglycerides (TG) from vegetable oils or animal fats with an alcohol (usually $\mathrm{MeOH}$ ) in presence of a catalyst $[1,2]$. Reaction products are methyl esters or $B D$, glycerol $(G L Y)$, soaps, rest of monoglycerides $(M G)$, diglycerides $(D G), T G$, catalyst, water and solvent $[3,4]$.

$\mathrm{MeOH}$ is not renewable, whereas EtOH has a sustainable character, which has attracted the attention of several researchers [1-3, 5-10]. There is a number of advantages of using EtOH rather than $\mathrm{MeOH}$ to $\mathrm{BD}$ manufacture [1, 7-9]; however, ethyl esters produce a major miscibility region of reaction products that make it difficult their separation. When the volumetric ratio of EtOH exceeds $30 \%$ just a single phase is obtained $[8,9]$. EtOH containing even low water amounts produces highly stable emulsions due to a higher content of soaps formed during the reaction $[6,9]$ and serious difficulties of separation $[7,13]$. Therefore, water traces should be minimized in BD synthesis when $\mathrm{EtOH}$ is used $[13,14]$. Other drawback is caused by the higher solubility of $G L Y$ in ethyl esters than in

Received: April 28, 2016; revised: March 06, 2017; accepted: April 21, 2017

This article has been accepted for publication and undergone full peer review but has not been through the copyediting, typesetting, pagination and proofreading process, which may lead to differences between this version and the final Version of Record (VOR). This work is currently citable by using the Digital Object Identifier (DOI) given below. The final VoR will be published online in Early View as soon as possible and may be different to this Accepted Article as a result of editing. Readers should obtain the final VoR from the journal website shown below when it is published to ensure accuracy of information. The authors are responsible for the content of this Accepted Article.

To be cited as: Chem. Eng. Technol. 10.1002/ceat.201600257

Link to final VoR: https://doi.org/10.1002/ceat.201600257

This article is protected by copyright. All rights reserved. 
methyl esters. This represents an additional drawback because it is necessary to make several hot water washes for purification of BD (10 L of water is needed to wash $1 \mathrm{~L}$ of methyl esters) [15].

Recent developments have heightened the need of applying membrane technology in BD production and purification [2,16-21]. Dubé [16] have informed BD synthesis from Canola oil and $\mathrm{MeOH}$ using acid and basic catalysts in a semi-batch membrane reactor. Wang [17] used ceramic membranes of MF to purify methyl esters obtained from palm oil. GLY remained emulsified in BD phase in drops of $2.2 \mu \mathrm{m}$ diameter. Other researchers [18] studied the GLY separation from BD using commercial ceramic membranes of $\mathrm{Al}_{2} \mathrm{O}_{3} / \mathrm{TiO}_{2}$ with different pore sizes ranging 0.2 to $0.8 \mu \mathrm{m}$. Feed solution was prepared adding $G L Y$ and EtOH to commercial purified BD [22] with low fluxes obtained due to fouling. An emulsion of BD containing $0.05 \% \mathrm{GLY}$ and $0.2 \%$ water was filtrated by Saleh [19] using a commercial UF membrane. The permeation was carried out in a cross-flow cell. GLY was successfully separated meting the ASTM 6584 standard.

The polymeric membrane material can be affected by BD permeation as it was reported by Othman [20]. Apparent $p H\left(p H_{a p p} \sim 12.4\right)$ of real BD solution must to be modified at values of $p H_{a p p} \sim 8.7$ in order to prevent physical damages of commercial membranes. In such conditions, membrane performance allows to reject $70 \%$ of $G L Y$ and $40 \%$ of $M G$. Recently, mixed matrix membranes containing nanotubes were applied to BD purification using a dead-end flow cell [21]. The authors report a $100 \%$ of glycerol removal low recovery of solvent after the permeation of biodiesel (irreversible fouling). These previous studies reveal that BD purification using membrane technology is a complex process that needs further research. The aim of this paper is to explore the performance of lab-made composite membranes for BD purification. For that, two solvent resistant nanofiltration composite membranes from PVDF and PDMS were used for BD purification. BD solutions obtained at lab via transesterification of soybean oil with $\mathrm{EtOH}$ were used in the permeation tests.

\section{Experimental}

\subsection{Reagents}

The catalyst, $\mathrm{NaOH} 97 \%$ wt, was purchased to Ciccarelli (Argentina). Semi-refined soybean oil was kindly provided by Oleaginosa Cabrera SAIC (Argentina). Some compounds of interest in the semirefined oil are: Soap $=0.01 \% \mathrm{wt}$, FFA (free fat acids) $=0.14 \pm 0.02 \% \mathrm{wt}, H$ (humidity) $=0.15 \pm 0.01 \%$ wt, $\eta$ (viscosity) $=44 \pm 1 \mathrm{cP}$ and $\rho$ (density) $=0.915 \mathrm{Kg} \mathrm{m}^{-3}$. Ethanol used for the biodiesel synthesis and the permeation experiments was obtained from Bio4 S.A. Argentina. The EtOH characteristics obtained from lab analysis shown an acidic content (as acetic acid) $<20$ ppm, $H=0.60 \pm 0.05 \%$ wt and $\rho=0.79 \mathrm{Kg} \mathrm{m}^{-3}$. Sintorgan (Argentina) provided isopropanol and $\mathrm{n}$-hexane analytical grade. 1,2,4Butanetriol (1000 $\mathrm{g} \mathrm{mL}^{-1}$ in pyridine) and Tricaprin (8000 $\mathrm{g} \mathrm{mL}^{-1}$ in pyridine) $G L Y\left(500 \mu \mathrm{g} \mathrm{m}^{-1}\right.$ in pyridine); MG, DG, and TG (500 $\mathrm{g} \mathrm{mL}^{-1}$ in pyridine), were purchase to Sigma-Aldrich. N-Methyl-N(trimethylsilyl) trifluoroacetamide (MTFA) 98,5\% was used as a silylating agent whereas anhydrous heptane was used as solvent (Sigma-Aldrich). For the humidity determination (Karl Fischer) HYDRANAL ${ }^{\circ}$ reagent was purchased from Sigma Aldrich (Argentina). $\mathrm{HCl}(36.5 \%)$ and potassium biphthalate were provided by Cicarrelli (Argentina).

The materials used in the composite membrane preparation were non-woven Viledon 2431 support provided by Carl Freudenberg (Weinheim, Germany), PVDF high viscosity Solef ${ }^{\circ} 1015$ supplied by Solvay (Brussels, Belgium), dimethylformamide (DMF) and tetrahydrofuran (THF) were purchased from Aldrich (Buenos Aires, Argentina). The coating material was commercial PDMS provide by Siloc (Anaeróbicos S.A., Argentina).

Dyes Methylene Blue (MB) (MW $374 \mathrm{~g} \mathrm{gmol}^{-1}, 99 \%$ ) and Rose Bengal (RB) (MW $1017 \mathrm{~g} \mathrm{gmol}^{-1}, 99 \%$ ) were used in the membrane MWCO experiments. MB was purchased, from Anedra S.A. (Argentina) and RB from Cicarelli (Argentina). 


\subsection{Membranes preparation and characterization}

Membrane preparation: Composite membranes were performed by covering with a thin layer of polymeric material the surface of an asymmetric membrane (AM) of PVDF according to Firman [23]. The AM was synthesized by phase inversion process. Two NF composite membranes resistant to organic solvents, denoted as PVDF-10SI and PVDF-12SI, were prepared by covering the surface of the AM with $10 \%$ and $12 \%$ wt PDMS solutions in hexane, respectively.

MWCO evaluation: There are several factors involved in the MWCO determinations when solute rejection technique is used, among them: interactions between de solutes-solvent-membrane materials; size, charge and shape of the molecules; swelling effect; etc. Several works has been reported in order to establish characteristic parameters of the UF and NF systems (permeate flux and rejection coefficient) [24-28]. From these experimental observations it was clear that the solute rejection was dependent strongly on both the type of solvent and the membrane.

Many researchers have used organic dyes rejections to compare the properties of SRNF membranes [29-32]. In order to standardize the determination of the MWCOs of our SRNF membranes, dye rejection technique based on a $90 \%$ retention was used [23]. Two organic solutes with molecular weight in the range of NF application (i.e. 300-1000 $\mathrm{g} \mathrm{gmol}^{-1}$ ) have been selected: MB (MW $374 \mathrm{~g}$ $\mathrm{gmol}^{-1}$ ) and RB (MW $1017 \mathrm{~g} \mathrm{gmol}^{-1}$ ). The dyes rejections have been studied using solutions of low concentration of RB and MB in ethanol solvent $\left(\sim 10^{-4}-10^{-5} \mathrm{M}\right)$. Ethanol was selected because it was used in the biodiesel synthesis and the permeability tests.

To determine the molecular weight cutoff of the membrane, ethanol solutions of $\mathrm{MB} 7.5 \times 10^{-5} \mathrm{M}$ and RB $5.5 \times 10^{-5} \mathrm{M}$ were permeated in the dead-end setup described in Sect. 2.4. Prior to permeation, membranes were conditioned with $\mathrm{EtOH}$ for $24 \mathrm{~h}$ at $20^{\circ} \mathrm{C}$. The dye permeations were performed at $20^{\circ} \mathrm{C}, \Delta p=10$ bar. After the steady state of permeation flux was reached ( $40 \mathrm{~min}$ ), the dye concentrations in the permeate $\left(C_{i}^{P}\right)$ and retentate $\left(C_{i}^{R}\right)$ were determined with an UV-Vis Metrolab 330 spectrophotometer (664 $\mathrm{nm}$ and $548 \mathrm{~nm}$ for MB and RB respectively) [23]. The values of Dye rejections, $\% R_{i}$, were calculated according to $\mathrm{Eq}$. (5) where $\mathrm{i}=\mathrm{RB}$ or $\mathrm{MB}$.

Contact angle measurements: In order to evaluate the hydrophilicity/hydrophobicity of membrane, contact angle measurements of the surface of the membranes with water were performed using a Micromeritics (1501) anglometer.

SEM measurements: The composite membrane surface and cross section morphologies were observed using a scanning electron microscope (SEM) LEO 1450VP. For the SEM morphological surface and cross section analysis, samples were coated by sputtering a thin gold layer.

\subsection{Synthesis and analysis of BD}

In the BD synthesis, $1 \mathrm{Kg}$ of semi-refined soybean oil was loaded into a glass balloon ( $2 \mathrm{~L}$ ) and placed in a rotational evaporator. The oil temperature was kept constant at $55^{\circ} \mathrm{C}$ under continuous stirring. The catalyst sodium ethylate (EtONa) was prepared by reacting $10.5 \mathrm{~g} \mathrm{NaOH}$ in $325 \mathrm{~mL}$ of EtOH. Once the formation of EtONa was completed, it was mixed with the semi-refined oil under stirring ( 100 $\mathrm{rpm}$ ). The molar ratio between alcohol and triglycerides (oil) was 6:1. After $2 \mathrm{~h}$ of reaction, the mixture was transferred to a separating funnel of $2 \mathrm{~L}$. Two separated phases at room temperature $\left(20^{\circ} \mathrm{C}\right)$ was observed, one rich in ethyl esters (BD) and the other one rich in glycerol. The latter was discarded. The ethyl esters phase was divided in two aliquots; one was used as it was obtained, and the excess of EtOH was eliminated in the other one. EtOH was removed by evaporation at reduced pressure $\left(50^{\circ} \mathrm{C}, 120\right.$ torr). Both aliquots, $\mathrm{BD}$ with and without $\mathrm{EtOH}$, were used in the permeation experiments, see Sect. 3.2.

The content of $G L Y, M G, D G$ and TG, was conducted based on ASTM D 6584 method. Gas chromatography assays were performed in a Perkin Elmer Clarus 580, with a flame detector (FID). In 
order to adequately quantify the concentration of these compounds, four calibration curves was performed $\left(R^{2}>0.998\right)$. Experimentally, appropriate amounts of internal standard (tricaprin and 1,2,4-butanetriol) were placed in a $10 \mathrm{~mL}$ vial. Then the silylating agent (MTFA) in pyridine was added. After $20 \mathrm{~min}$ at $40{ }^{\circ} \mathrm{C}$ the mixture was diluted with $\mathrm{n}$-heptane. Finally, sample injections were made in the on-column mode $(1 \mu \mathrm{L})$. The values of $G L Y, M G, D G$ and $T G$ obtained from the calibration curves are expressed in \% wt. GT (total glycerides) values were calculated from

$$
G T=G L Y+\sum 0.2591 M G+\sum 0.1488 D G+\sum 0.1044 T G
$$

Humidity determinations were performed with an automatic volumetric Karl Fischer titrator Titrino Metrohm KF-870 plus. For determination of soap as sodium oleate the AOCS method modified was used [33]. The technique was carried out with an automatic titrator plus Metrhom Titrino, equipped with a Solvotrode Metrohm electrode for non-aqueous determinations. The content of ethyl esters expressed as \%EE was calculated from:

$$
\% E E=100+G L Y+M G+D G+T G-\% \text { Soap }-\% H-\% E t O H)
$$

\subsection{Filtration device}

All permeation experiments were performed in a dead-end filtration set-up described elsewhere [23]. The stainless steel 316L test cell (Sterlitech HP 4750, USA) has an inner diameter of $5.1 \mathrm{~cm}$ and height of $19.9 \mathrm{~cm}$. The composite membrane was supported on a sintered porous stainless-steel disc. Membrane diameter was $4.9 \mathrm{~cm}$ with an effective area $A=14.6 \times 10^{-4} \mathrm{~m}^{2}$. To minimize the fouling phenomena the feed solution was stirred with a magnetic bar $(500 \mathrm{rpm})$ placed over the membrane surface. Transmembrane pressure $(\Delta p)$ was supplied by a nitrogen cylinder connected to the top of the cell. The experimental temperature was kept constant by the temperature-controller of the magnetic stirrer. Permeate flux $J\left(\mathrm{~L} \mathrm{~m}^{-2} \mathrm{~h}^{-1}\right)$ was determined by measuring the permeate solvent volume accumulated $(\Delta V)$ during the operation time $(\Delta t)$ and calculated from:

$J=\frac{1}{A} \frac{\Delta V}{\Delta t}$

\subsection{BD and EtOH permeation tests}

\subsubsection{EtOH permeability.}

The permeation tests were performed in triplicate, in the dead-end filtration cell, see Sect. 2.4. The unit was operated in batch mode by charging the reservoir cell with pure organic solvent, and the

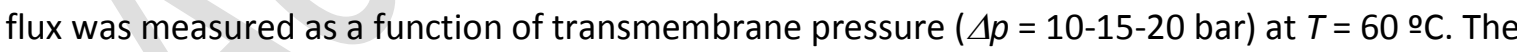
permeate flux values $(J)$ were calculated from Eq. (3). The $J$ data were used to evaluate $\mathrm{EtOH}$ permeability, $L_{E T O H}\left(\mathrm{~L} \mathrm{~m}^{-2} \mathrm{~h}^{-1}\right.$ bar), from the slope of $J \mathrm{vs} \Delta p$ according to:

$$
L_{E t O H}=\frac{J}{\Delta p}
$$

The flux recovery ratio $(F R R)$ was calculated as the ratio between $L_{E t O H}^{*}$ and the permeability of the virgin membrane $\left(L_{E t O H}\right)$.

\subsubsection{BD permeation flux.}

Previous to BD permeation tests, the membranes were stabilized within the cell using ethanol for 24 hours. Then, the cell reservoir was charged with $270 \mathrm{~mL}$ of crude BD and stirred at a constant speed of $500 \mathrm{rpm}$. After an optimization, the selected parameters for the tests were: transmembrane 
pressure $(\Delta p=15$ and 20 bar $)$ and operating temperature $\left(T=60^{\circ} \mathrm{C}\right)$. The concentrations of BD compounds in the retentate and permeate were determined at the end of the permeation experiments ( $\approx 120 \mathrm{~min}$, steady-state conditions). The separation efficiency was calculated according to the percentages of retained GLY, GT and Soap, expressed as rejection factor as follows:

$$
\% R_{i}=\left(1-\frac{C_{i}^{P}}{C_{i}^{R}}\right) \times 100
$$

where the subscript i denoted the BD compounds (GLY, GT and Soap); and the superscripts $P$ and $R$ indicated the permeate and retentate solutions respectively.

\subsubsection{Membrane stability.}

Membranes were reused after each permeation experiment. In order to reach the initial membrane solvent flux, membranes were cleaned in situ with $270 \mathrm{~mL}$ of EtOH and allowed to permeate for 10 minutes at $60^{\circ} \mathrm{C}$ and 10 bar. After that, the ethanol permeability $\left(L_{E t O H}^{*}\right)$ was evaluated to establish a standard of membrane cleanliness. With the purpose of examine membrane stability; cycles of BD permeation followed of EtOH solvent permeation were carried out. The membrane integrity was determined by FTIR-ATR analysis using a FTIR Spectrum Two (Perkin Elmer).

\section{Results and discussion}

\subsection{Membrane Parameters.}

The membrane parameters are given in Tab. 1 . The dye rejection values $\left(R_{M B} \approx 32 \% ; R_{R B} \approx 60 \%\right)$ obtained for PVDF-10SI indicate that this membrane have a MWCO higher than $1000 \mathrm{Da}$. From the dye rejection factors of the PVDF-12SI $\left(R_{M B} \approx 75 \% ; R_{R B} \approx 92 \%\right)$ a MWCO of 1000 Da was evaluated. The rejection results showed the expected trend for both NF membranes, increasing the MW of dye components leads to increase in the membrane rejections. These results indicated that PVDF-10SI has higher pore sizes than the PVDF-12SI. This outcome is supported by the ethanol permeability tests (Table 1), in which the ethanol permeability of PVDF-10SI membrane is higher than PVDF-12SI one.

The values of contact angle for pure polymers denote the semi hydrophilic character of PVDF $(\theta=$ $\left.62^{\circ}\right)$ and the hydrophobic character of PDMS $\left(\theta=120^{\circ}\right)$ [23]. It can be seen from Tab. 1 the surface of composite membranes have hydrophobic nature $\left(\theta>90^{\circ}\right)$. There is a consistent increase in the hydrophobic character with the increasing percentage of the PDMS $\left(\theta=103^{\circ}\right.$ and $117^{\circ}$ for $\mathrm{SI}=10$ and $12 \%$, respectively).

"(Table 1)"

Cross section micrograph of PVDF-12SI composite membrane (Fig. 1) shows two well defined regions, a thicker macrostructure type finger like formed by the asymmetric PVDF membrane (support), and a thin dense selective layer produced by the coating material (PDMS). The figure shows there was not a clear boundary between the top layer and the PVDF support layer, indicating a tough adhesion between coating layer and support surface. Similar structure of the PVDF-10SI membrane was obtained. The coating layer thickness $(\ell)$ increase with the SI percentage, $\ell \approx 1 \mu \mathrm{m}$ and $\ell \approx 2.5 \mu \mathrm{m}$ for PVDF-10SI and PVDF-12SI respectively. The surface micrograph of 12SI-PVDF membrane shows a homogeneous texture, indicating a complete coating of the PVDF support with the PDMS material.

"(Figure 1)" 


\subsection{Biodiesel characteristics}

Two batches of biodiesel with the same initial concentration of reactants were prepared. After reaction and phase separation, two samples rich in ethyl esters, BD1 and BD2, were achieved. BD3 and BD4 solutions were obtained after EtOH evaporation of the BD1 and BD2 samples respectively. Tab. 2 shows the compositions of each BD sample after $48 \mathrm{~h}$ of settling at $20^{\circ} \mathrm{C}$. The high content of ethyl esters $~ 87 \% E E$, Eq. (2) and other minor components in BD solutions were similar to those reported by Kucek [6] and slightly higher than those found by Encinar [5]. BD1 and BD2 showed similar concentration of EtOH (7.8-8.2 \% v/v). As a result of ethanol evaporation, glycerol is separated, and in this way the final concentration was considerably reduced in BD3 and BD4 solutions $[8,9]$. All BD samples showed similar apparent $p H_{a p p}=11.7-12$ and $\rho=0.87-0.89 \mathrm{Kg} \mathrm{m}^{-3}$ values, and they were comparable to those published elsewhere [20]. The concentration of total glycerides were $(G T=0.73-2.07 \%)$ and Soap $=0.80-1.25 \%$. It is remarkable the difference between the values obtained in the present research and those achieved by Mendow [9]. According to their results the final content of soaps was $0.50 \%$ and total glycerol content of $0.40 \%$. These authors studied in depth the synthesis of $\mathrm{BD}$ from $\mathrm{EtOH}$, analyzing several variables (temperature, type of catalyst and EtOH concentration). In their work they used refined sunflower oil (FFA $<0.1 \%)$ and anhydrous EtOH $(H<0.115 \%)$. Therefore, the high concentration of glycerides and soaps obtained in the present research can be attributed to the high humidity content in the $\mathrm{EtOH} \sim 0.60 \%$ used in the catalyst preparation.

\section{"(Table 2)"}

In Fig. 2 potentiometric titration of soaps is shown. All biodiesel solutions have a single final point (black curve); however, two points should be expected: one for the catalyst and the other one for the soaps. To verify this, extra EtONa was added to BD solution and two points were found after titration, indicating that catalyst was consumed during the global reaction, confirming the excessive formation of soaps due to hydrolysis of triglycerides.

“(Figure 2)"

\subsection{BD permeability and membrane stability}

\subsubsection{BD permeability.}

All permeation trials were carried out in triplicate and mean values of permeate flux $(J)$ with time determined by Eq. (3) were reported in Fig. 3. The standard deviation (SD) from the data was of $4 \%$ after 30 min of permeation, indicating a good reproducibility of results. During the first 20 minutes there was a moderate drop in permeate flux of about 12 to $30 \%$, and then a constant flow of permeate. This decrease in the initial flow can be attributed to the membrane fouling (soap primary adsortion and concentration polarization effects). The average permeate flux values between $60 \mathrm{~min}$ and $120 \mathrm{~min}, J^{*}$, were used as reference fluxes to evaluate the membrane permselectivity performance. Tab. 3 summarises the average values of $J^{*}$ at $60{ }^{\circ} \mathrm{C}, 15$ and 20 bar. Unexpectedly, when BD solution was permeated through PVDF-12SI (higher MWCO) higher permeate flux than PVDF-10SI (lower MWCO) was measured. These results could be partially explained considering the existence of interactions between the different components. Researchers have been reported [32, 34] that complex solutions permeation can be affected by solute-solvent-membrane interactions due to changes in hydrophobicity of membranes and in solute or solvent polarizability. The results indicate that BD solution has higher permeate flux due to more affinity BD solution to PVDF-12SI. As it is expected, permeate flux increases as transmembrane pressure increases. It was observed that $\mathrm{EtOH}$ presence in BD solution produces a higher permeate flux in all assays performed. This can be 
explicated considering the decrease of both, the polarizability (EtOH 4.94, Methyl linoleate 36.15, GLY 7.92) [35] and the viscosity of BD solution in presence of EtOH.

"(Figure 3)"

In Tab. 3, the experimental results of rejection factors $(\% R)$ in quasi-steady state conditions (120 min) are shown. The standard deviation (SD) was $\pm 3-5 \%$. PVDF-12SI membrane had a higher retention values for GLY, GT and Soap than PVDF-10S, for feed BD solutions with and without EtOH. The best performance was obtained at 15 bar, to achieving the best rejection coefficient of $70 \%$ for GLY. At the same pressure, $\% R$ were slightly similar for PVDF-12SI. However, $\% R$ for PVDF-10SI membrane were appreciably diminished in feed solution without $\mathrm{EtOH}$, indicating that there is some affinity between the EtOH and BD components. In this case, the transport of GLY, GT and Soap through the membranes is enhanced by the $\mathrm{EtOH}$, diminishing the rejection factors. An increased in the transmembrane pressure leads to an increase of permeate flux with simultaneous decline in the rejection coefficients. This trend follows the usual behavior of the permeation processes driven by pressure; at higher permeation flux, the lower is the separation factor. Zeman [36] established that this behavior is due to the phenomenon of concentration polarization.

Commercial membrane Solsep has been studied by Othman [20]. Their results showed a good performance and stability in the treatment of $\mathrm{BD}$ by using $\mathrm{MeOH}$. Rejection coefficient reported by these researchers were $70 \%$ GLY, MG 40\%, DG 90\% y TG $100 \%$ with a permeate flux $30 \mathrm{~L} \mathrm{~m}^{-2} \mathrm{~h}^{-1}$ at $40^{\circ} \mathrm{C}$ and 6 bar. The results of this research using BD obtained from EtOH and PVDF-12SI membrane had similar separation performance, GLY 70\%, GT 69\% (MG 49\%, DG 79\% and TG $100 \%$ ) at $60{ }^{\circ} \mathrm{C}$ and 15 bar of transmembrane pressure.

"(Table 3)"

\subsubsection{Membrane Stability.}

Ethanol permeability $\left(L_{E t O H}\right)$ values determined at $60^{\circ} \mathrm{C}$ are shown in Tab. 1. PVDF-10SI showed higher $L_{E T O H}$ value than PVDF-12SI. $L_{E t O H}$ values follow the same trend as membranes CUTOFF. In order to observe membrane stability, cycles of BD permeation followed of EtOH flux determination were carried out. Tab. 1 shows the data of membrane permeability after 20 cycles $\left(L^{*}{ }_{E t O H}\right)$ and the $F R R$ of $\mathrm{EtOH}$. The remarkable FRR values (0.94-0.95) showed that PVDF-SI membranes attained high stability during the BD permeation process. Fig. 4 shows the FTIR-ATR spectra of PVDF-12SI before and after of 20 cycles of BD permeation. No changes in $-\mathrm{OH}\left(3300 \mathrm{~cm}^{-1}\right)$ bands neither $-\mathrm{CH}$ bands $(2900-3000$ $\mathrm{cm}^{-1}$ ) were observed. Also, Si-O-Si bands $\left(900-1100 \mathrm{~cm}^{-1}\right)$ were left unaltered by BD permeation, indicating that membranes were not chemically modified at this severe conditions $\left(p H_{a p p}=12\right.$ and $\left.60^{\circ} \mathrm{C}\right)[37,38]$.

"(Figure 4)"

\section{Conclusions}

PVDF membranes coated with a PDMS layer were prepared in order to be used in BD reactive medium for purify ethyl esters. SRNF membranes show very high stability in such severe conditions $p H_{a p p}=12$ and $60^{\circ} \mathrm{C}$. EtOH presence in BD solution has a little effect in rejection membrane coefficient whereas they were adversely affected by transmembrane pressure. Experiments carried out with PVDF-12SI at $60{ }^{\circ} \mathrm{C}, p H_{a p p}=12$ and 15 bar allow to achieve rejection coefficients of $70 \% G L Y$, 
$69 \%$ GT (MG 49\%, DG 79\% y TG $100 \%$ ) with a permeate flux of $7.4 \mathrm{~L} \mathrm{~m}^{-2} \mathrm{~h}^{-1}$. It is noteworthy the high stability showed by these membranes, reaching a FRR as high as 0.94-095 after 20 cycles of use.

Membranes obtained in this work can be used to purify BD due to their great stability with interesting retention coefficients. These improvements will substantially reduce operating and capital costs. It will also allow mitigate the environmental impact by reducing aqueous effluents.

\section{Symbols}

\begin{tabular}{|c|c|c|}
\hline$A$ & $\mathrm{~m}^{2}$ & Area \\
\hline$C_{i}^{P}$ & {$[\% \mathrm{wt}]$} & Concentration of permeate \\
\hline$C_{i}^{R}$ & {$[\% \mathrm{wt}]$} & Concentration of retentate \\
\hline$D G$ & {$[\% \mathrm{wt}]$} & Concentration of diglycerides \\
\hline FFA & {$[\% \mathrm{wt}]$} & Concentration of free fatty acid \\
\hline GLY & {$[\% \mathrm{wt}]$} & Concentration of free glicerol \\
\hline GT & {$[\% \mathrm{wt}]$} & Concentration of total glycerides \\
\hline$H$ & {$[\% w t]$} & Concentration of water \\
\hline$J$ & $\mathrm{~L} \mathrm{~m}^{-2} \mathrm{~h}^{-1}$ & Flux \\
\hline$J^{*}$ & $\mathrm{~L} \mathrm{~m}^{-2} \mathrm{~h}^{-1}$ & Flux in semi-stationary state \\
\hline$L$ & $\mathrm{~L} \mathrm{~m}^{-2} \mathrm{~h}^{-1}$ bar & Solvent permeability \\
\hline MG & {$[\% \mathrm{wt}]$} & Concentration of monoglycerides \\
\hline$p H_{a p p}$ & - & Apparent $\mathrm{pH}$ \\
\hline Soap & {$[\% \mathrm{wt}]$} & Concentration of soap \\
\hline$T$ & ${ }^{\circ} \mathrm{C}$ & Temperature \\
\hline$T G$ & {$[\% \mathrm{wt}]$} & Concentration of triglycerides \\
\hline$\ell$ & $\mu \mathrm{m}$ & Thickness of the membrane coating layer \\
\hline$\% E E$ & {$[\% \mathrm{wt}]$} & Content of ethyl ester \\
\hline$\% R_{i}$ & & Rejection efficiency \\
\hline$\Delta p$ & Bar & Transmembrane pressure \\
\hline$\Delta t$ & h & Time change \\
\hline$\Delta V$ & $\mathrm{~m}^{3}$ & Volume change \\
\hline \multicolumn{3}{|l|}{$\begin{array}{l}\text { Greek } \\
\text { symbols }\end{array}$} \\
\hline$\eta$ & $\mathrm{cp}$ & Viscosity \\
\hline$\rho$ & $\mathrm{Kg} \mathrm{m}^{-3}$ & Density \\
\hline$\theta$ & $\circ$ & Contact angle \\
\hline
\end{tabular}




\section{Acknowledgements}

This research was supported by ANPCyT-UNRC PICT 2144/11, PROICO 2-1712 UNSL, and PICT 2013 $\mathrm{N}^{\circ} 0367$.

\section{References}

[1] L.K. Patrylak, K.I. Patrylak, M.V. Okhrimenko, V.V. Ivanenko, S.O. Zubenko, A.M. Levterov, V.P. Marakhovskyi, V.D. Savytskyi, Fuel 2013, 113, 650-653. DOI:10.1016/j.fuel.2013.06.020

[2] N.N.A.N. Yusuf, S.K. Kamarudin, Z. Yaakub, Energy Convers. Manage. 2011, 52 (7), 2741-2751. DOI:10.1016/j.enconman.2010.12.004

[3] D.Y.C. Leung, X. Wu, M.K.H. Leung, Appl. Energy 2010, 87 (4), 1083-1095. DOI:10.1016/j.apenergy.2009.10.006

[4] F. Ma, M.A. Hanna, Bioresour. Technol. 1999, 70 (1), 1-15. DOI:10.1016/S0960-8524(99)00025-5

[5] J.M. Encinar, J.F. González, A. Rodríguez-Reinares, Fuel Process. Technol. 2007, 88 (5), 513-522. DOI:10.1016/j.fuproc.2007.01.002

[6] K.T. Kucek, M.A.F. César-Oliveira, H.M. Wilhelm, L.P. Ramos, J. Am. Oil Chem. Soc. 2007, 84 (4), 385-392. DOI:10.1007/s11746-007-1048-2

[7] A.B. Machado, Y.C. Ardila, L.H. de Oliveira, M. Aznar, M.R. Wolf Maciel, J. Chem. Eng. Data 2012, 57 (5), 1417-1422. DOI:10.1021/je201243u

[8] G. Mendow, C.A. Querini, Chem. Eng. J. 2013, 228, 93-101. DOI:10.1016/j.cej.2013.05.007

[9] G. Mendow, N.S. Veizaga, C.A. Querini, Bioresour. Technol. 2011, 102 (11), 6385-6391. DOI:10.1016/j.biortech.2011.01.072

[10] H. Uthman, A.S. Abdulkareem, Energy Sources, Part A. 2014, 36 (19), 2135-2141. DOI:10.1080/15567036.2011.563274

[11] M. Corp., Historical Methanex Posted Price Metanex, web. March 31, 2015.

[12] OECD-FAO Agricultural Outlook 2015, OECD Publishing, Paris. 2015 DOI:10.1787/agr_outlook2015-en.

[13] M.L. Klossek, J. Marcus, D. Touraud, W. Kunz, Colloids Surf. Physicochem. Eng. Aspects 2013, 427, 95-100. DOI:10.1016/j.colsurfa.2013.03.059

[14] S.J. Chen, D.F. Evans, B.W. Ninham, J. Phys. Chem. 1984, 88 (8), 1631-

1634.DOI:10.1021/j150652a038

[15] I.M. Atadashi, M.K. Aroua, A.A. Aziz, Renewable Energy 2011, 36 (2), 437-443.

DOI:10.1016/j.renene.2010.07.019

[16] M.A. Dube, A.Y. Tremblay, J. Liu, Bioresour. Technol.2007, 98 (3), 639-647.

DOI:10.1016/j.biortech.2006.02.019

[17] Y. Wang, X. Wang, Y. Liu, S. Ou, Y. Tan, S. Tang, Fuel Process. Technol. 2009, 90 (3), 422-427. DOI:10.1016/j.fuproc.2008.11.004

[18] M.C.S. Gomes, N.C. Pereira, S.T.D.d. Barros, J. Membr. Sci. 2010, 352 (1-2), 271-276.

DOI:10.1016/j.memsci.2010.02.030

[19] J. Saleh, A.Y. Tremblay, M.A. Dubé, Fuel 2010, 89 (9), 2260-2266. DOI:10.1016/j.fuel.2010.04.025

[20] R. Othman, A.W. Mohammad, M. Ismail, J. Salimon, J. Membr. Sci. 2010, 348 (1-2), 287-

297.DOI:10.1016/j.memsci.2009.11.012

This article is protected by copyright. All rights reserved. 
[21] M. Peyravi, A. Rahimpour, M. Jahanshahi, J. Membr. Sci. 2015, 473, 72-84. DOI:10.1016/j.memsci.2014.08.009

[22] X. Liu, X. Piao, Y. Wang, S. Zhu, J. Chem. Eng. Data 2008, 53 (2), 359-362. DOI:10.1021/je700382s

[23] L.R. Firman, N.A. Ochoa, J. Marchese, C.L. Pagliero, J. Membr. Sci. 2013, 431, 187-196. DOI:10.1016/j.memsci.2012.12.040

[24] Y. Koso, Y. Sugiura, T. Kitao, K. Nishimura, J. Membr. Sci. 2001, 192 (1/2), 1-10.

DOI:10.1016/S0376-7388(01)00411-2

[25] K.O. Ageson, J.L. Oh, T. Urase, J. Membr. Sci. 2003, 225 (1/2), 91-103.

DOI:10.1016/j.memsci.2003.08.006

[26] A.D. Revchuk, I.H. Suffet. Water Res. 2009, 43 (15), 3685-3692.

DOI:10.1016/j.watres.2009.05.029

[27] P. Marchetti, M.F. Jimenez-Solomon, G. Szekely, A.G. Livingston, Chem. Rev. 2014, 114 (21), 10735-10806. DOI:dx.doi.org/10.1021/cr500006j

[28] A. M. Hidalgo, M. Gómez, M. D. Murcia, E. Gómez, G. León, E. Cascales, Chem. Eng. Technol. 2016, 39 (6), 1177-1184. DOI: 10.1002/ceat.201500254

[29] M.G. Buonomenna, G. Golemme, J.C. Jansen, S.-H. Choi, J. Membr. Sci. 2011, 368 (1/2), 144-149. DOI:10.1016/j.memsci.2010.11.036

[30] N. A. A. Sani, W. J. Lau, A. F. Ismail, Jurnal Teknologi. 2014, 70 (2), 29-32. DOI: 10.11113/jt.v70.3431

[31] S. Darvishmanesh, J. Degreve, B. Van der Bruggen, Phys. Chem. Chem. Phys. 2010, 12 (40), 13333-13342. DOI:10.1039/c0cp00230e

[32] S. Postel, G. Spalding, M. Chirnside, M. Wessling, J. Membr. Sci., 2013, 447 (1), 57-65. DOI:10.1016/j.memsci.2013.06.009

[33] V. C. Mehlenbacher. Official Methods and Recommended Practices of the AOCS. Method Cc 1795, 6 ed., AOCS Press, 2009.

[34] A. Volkov, A. Yushkin, Y. Kachula, V. Khotimsky, V. Volkov, Sep. Purif. Technol. 2014, 124, 43-48. DOI:10.1016/j.seppur.2013.12.044

[35] R. Bosque, J. Sales, J. Chem. Inf. Comput. Sci. 2002, 42 (5), 1154-1163. DOI:10.1021/ci025528x

[36] L. Zeman, M. Wales, Sep. Sci. Technol. 1981, 16 (3), 275-290. DOI:10.1080/01496398108068519

[37] E.A. Romanenko, B.V. Tkachuk, J. Appl. Spectrosc. 1973, 18 (2), 188-192.

DOI:10.1007/BF00604710

[38] E.P. Plueddemann, Silane Coupling Agents, 1st ed., Springer, New York, 1982. 


\section{Figures}

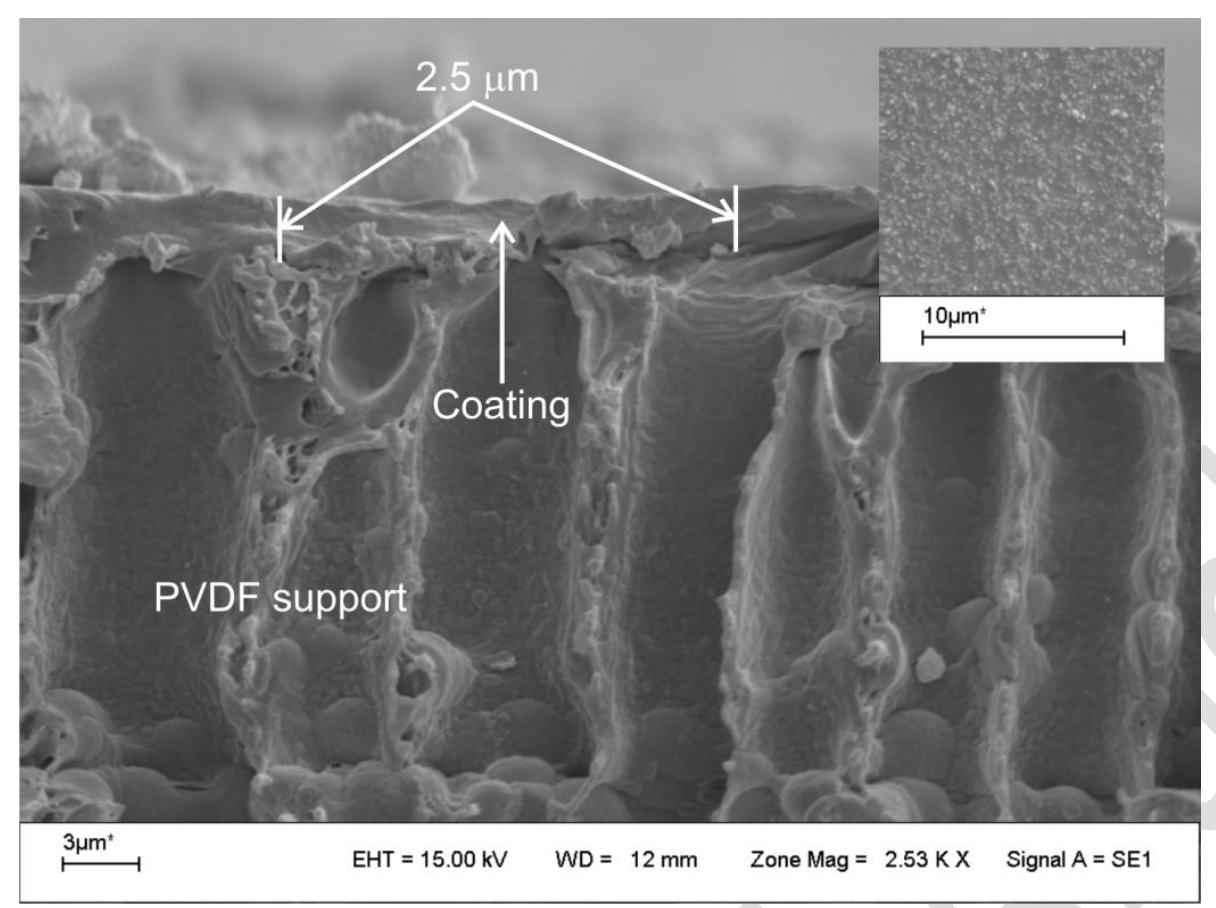

Figure 1. Cross section and surface (insert) SEM micrographs of PVDF-12SI membrane.

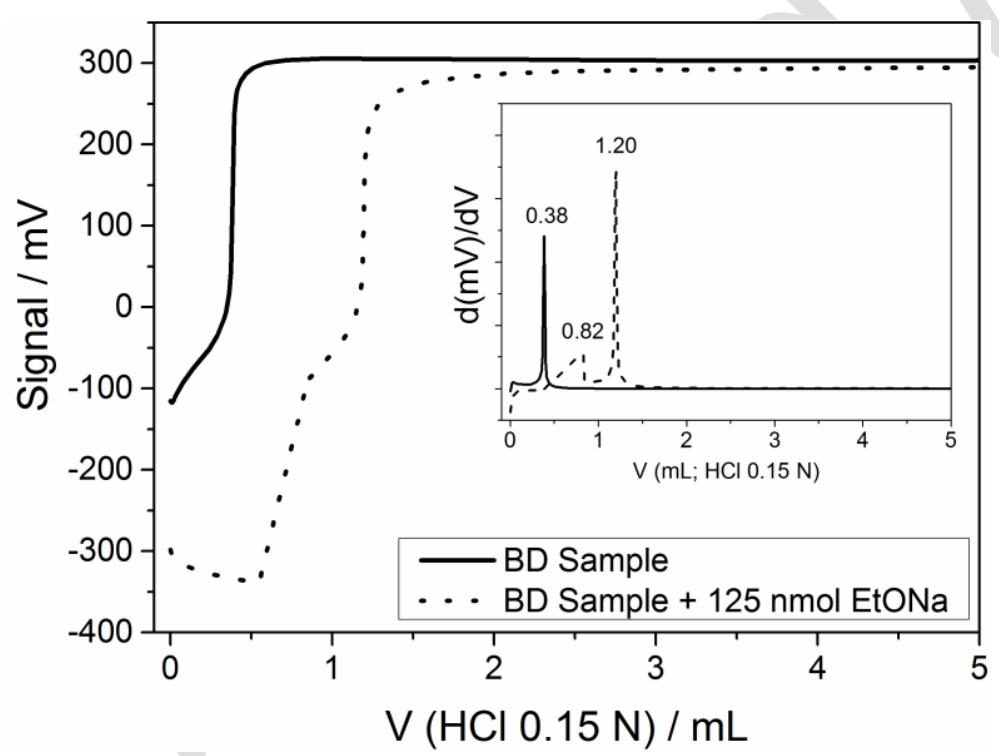

Figure 2. BD Potentiometric titration. Insert: Numerical differentiation of potentiometric data. 

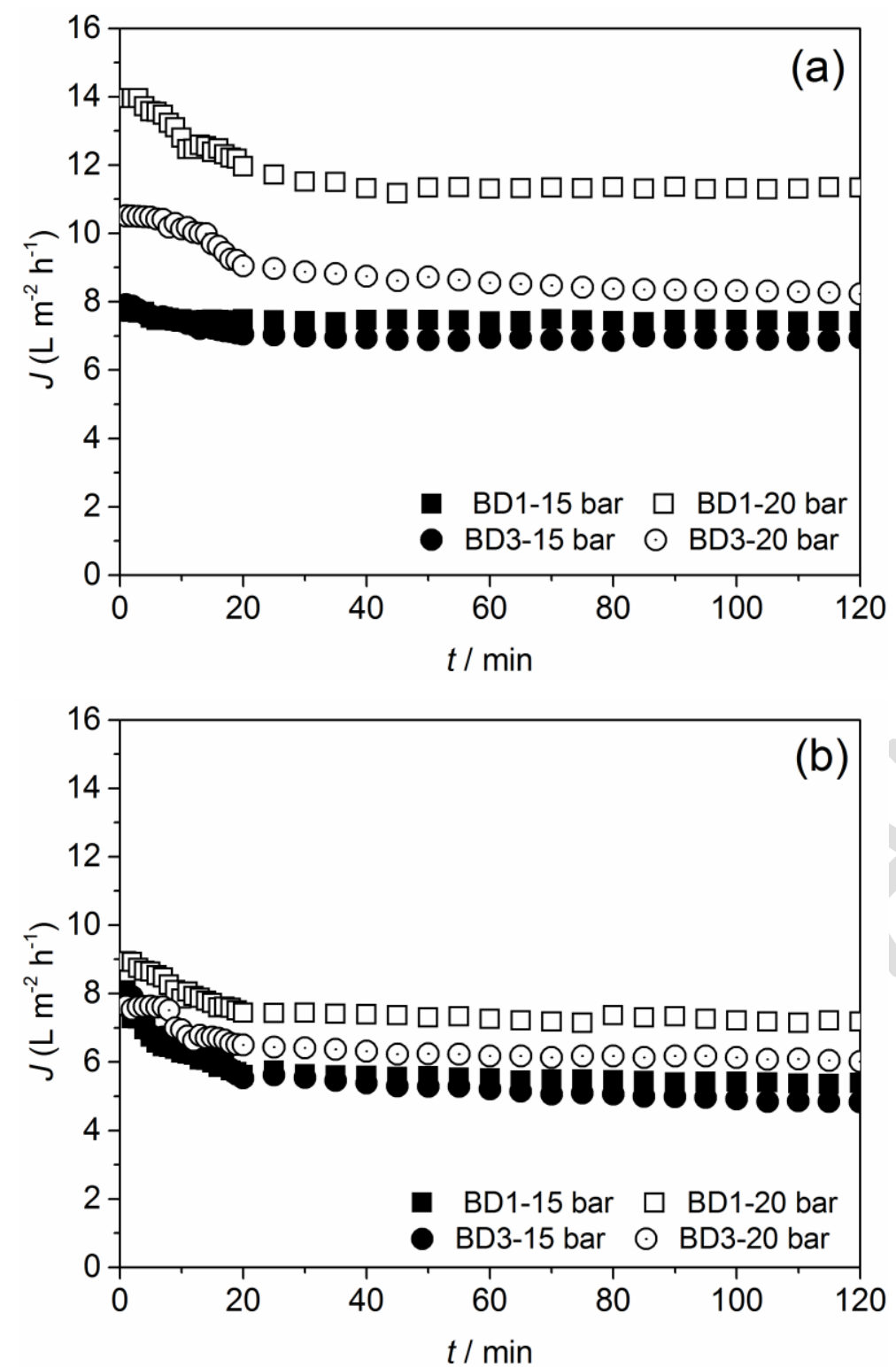

Figure 3- Permeation profiles for BD. a) PVDF-12SI; b) PVDF-10SI. 


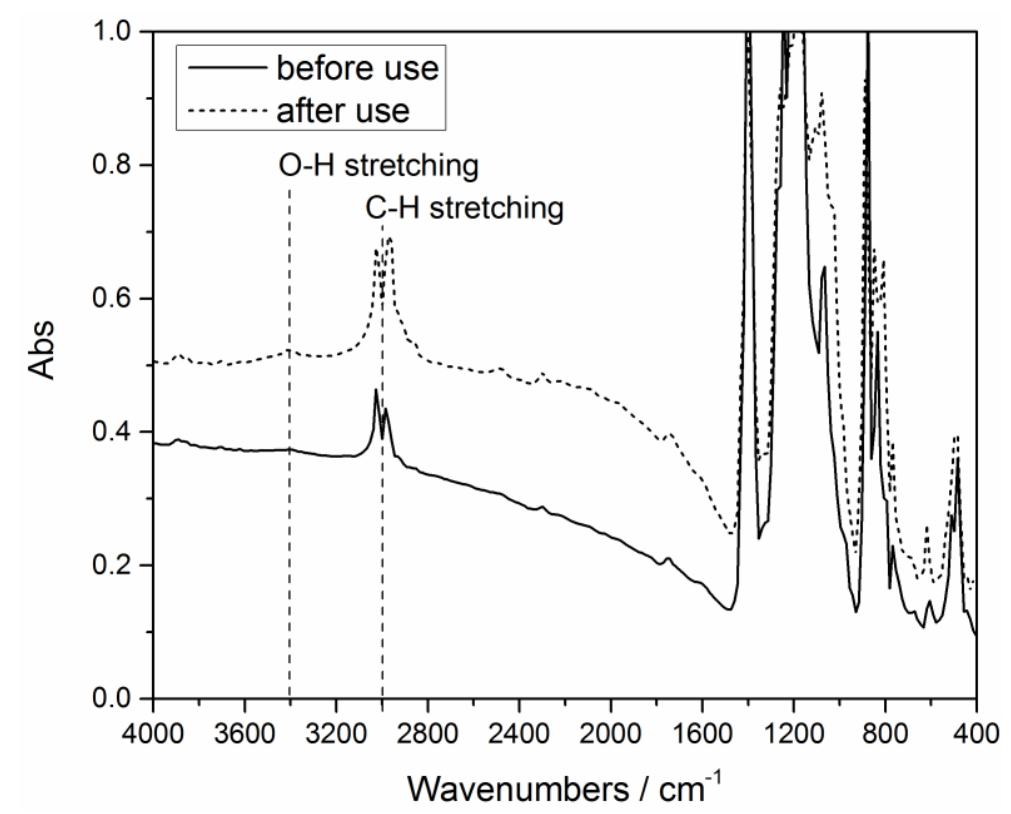

Figure 4. FTIR of PVDF-12SI membrane before and after 20 permeation cycles. 


\section{Tables}

Table 1. Membrane parameters and ethanol permeability $\left(T=60^{\circ} \mathrm{C}\right)$.

\begin{tabular}{|c|c|c|c|c|c|c|}
\hline Membrane & $\theta$ & MWCO (Da) & $\ell \times 10^{-6}(\mathrm{~m})$ & $\begin{array}{l}L_{E t O H} \\
\left(\mathrm{~L} \mathrm{~m}^{-2} \mathrm{~h}^{-1} \operatorname{bar}^{-1}\right)\end{array}$ & $\begin{array}{l}L_{\text {EtOH }}^{*} \\
\left(\mathrm{~L} \mathrm{~m}^{-2} \mathrm{~h}^{-1} \operatorname{bar}^{-1}\right)\end{array}$ & $\begin{array}{l}F R R \\
L_{E t O H}^{*} / L_{E t O H}\end{array}$ \\
\hline PVDF-12SI & $117 \pm 4$ & $\approx 1000$ & $2.5 \pm 0.1$ & $5.50 \pm 0.66$ & $5.25 \pm 0.50$ & $0.95 \pm 0.10$ \\
\hline PVDF-10SI & $103 \pm 3$ & $>1000$ & $1.0 \pm 0.1$ & $6.60 \pm 1.10$ & $6.19 \pm 0.95$ & $0.94 \pm 0.22$ \\
\hline
\end{tabular}

Table 2. Characteristics of synthesized BD.

\begin{tabular}{|c|c|c|c|c|c|c|c|c|c|c|c|}
\hline \multirow{2}{*}{ BD } & $\mathrm{EtOH}$ & Soap & $p H_{a p p}$ & \multirow{2}{*}{$\begin{array}{l}\rho \\
\mathrm{Kg} / \mathrm{m}^{3}\end{array}$} & \multirow{2}{*}{$\begin{array}{l}H \\
\% w / w\end{array}$} & \multirow{2}{*}{$\begin{array}{l}\text { GLY } \\
\% w / w\end{array}$} & \multirow{2}{*}{$\begin{array}{l}M G \\
\% \mathrm{w} / \mathrm{w}\end{array}$} & \multirow{2}{*}{$\begin{array}{l}D G \\
\% \mathrm{w} / \mathrm{w}\end{array}$} & \multirow{2}{*}{$\begin{array}{l}\text { TG } \\
\% \mathrm{w} / \mathrm{w}\end{array}$} & \multirow{2}{*}{$\begin{array}{l}\text { GT } \\
\% w / w\end{array}$} & \multirow[t]{2}{*}{$\% E E$} \\
\hline & $\% v / v$ & $\% w / w$ & & & & & & & & & \\
\hline BD1 & 7.8 & 1.06 & 11.9 & 0.89 & 0.15 & 1.31 & 1.55 & 0.15 & 0.03 & 1.74 & 87.9 \\
\hline BD2 & 8.2 & 1.25 & 12.0 & 0.88 & 0.11 & 1.63 & 1.42 & 0.43 & 0.08 & 2.07 & 86.9 \\
\hline BD3 & 1.6 & 0.80 & 11.7 & 0.87 & 0.03 & 0.29 & 1.63 & 0.12 & 0.04 & 0.73 & 95.5 \\
\hline BD4 & 1.7 & 0.98 & 11.8 & 0.87 & 0.04 & 0.32 & 1.75 & 0.10 & 0.02 & 0.79 & 95.1 \\
\hline
\end{tabular}

Table 3. BD permeation fluxes at steady state and rejection factors.

\begin{tabular}{|c|c|c|c|c|c|c|}
\hline BD & Membrane & (bar & $\left(L \mathrm{~m}^{-2} \mathrm{~h}^{-1}\right)$ & $\% R_{G L Y}$ & $\% R_{G T}$ & $\% R_{\text {soap }}$ \\
\hline \multirow{2}{*}{ BD1 } & & 15 & $7.4 \pm 0.5$ & 70.5 & 69.2 & 40.4 \\
\hline & & 20 & $10.8 \pm 0.9$ & 28.4 & 23.5 & 44.5 \\
\hline \multirow{2}{*}{ BD2 } & & 15 & $5.5 \pm 0.4$ & 47.2 & 45.7 & 38.3 \\
\hline & נטגו- & 20 & $7.3 \pm 0.4$ & 28.5 & 22.3 & 40.6 \\
\hline \multirow{2}{*}{ BD3 } & & 15 & $6.9 \pm 0.3$ & 68.7 & 59.7 & 30.8 \\
\hline & ו & 20 & $8.5 \pm 0.5$ & 52.3 & 32.7 & 35.7 \\
\hline \multirow{2}{*}{ BD4 } & DYDE 10 & 15 & $5.2 \pm 0.4$ & 16.8 & 30.8 & 26.5 \\
\hline & & 20 & $6.2 \pm 0.3$ & 10.4 & 13.5 & 29.0 \\
\hline
\end{tabular}

This article is protected by copyright. All rights reserved. 


\section{TOC text:}

Nanofiltration polymeric membranes has become a viable and efficient way for the purification of biodiesel. The purification of crude biodiesel with membranes studied in this work has been relevant, and has shown a separation of over a third of glycerides with high resistance to degradation.

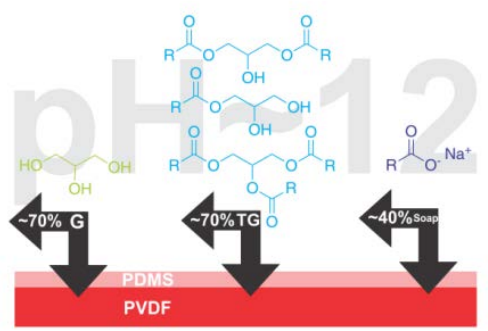

This article is protected by copyright. All rights reserved. 